\title{
Analysis of Uterine Rupture in Pregnancy at a Tertiary Care Hospital
}

\author{
Beemba Shakya \\ Paropakar Maternity and Women's Hospital, Thapathali, Kathmandu \\ Received: 1 May 2019 \\ Accepted: 15 May 2019 \\ DOI: https://doi.org/10.3126/njog.v14i1.26623
}

ABSTRACT

Aims: To analyze patients with uterine rupture in pregnancy

Methods: This was a cross-sectional retrospective study undertaken at Paropakar Maternity and Women's Hospital. Two years' medical records of uterine rupture between 14 April 2017 and 13 April 2019 were reviewed. Information on patient characteristics, age, parity, mode of previous deliveries, onset of labour spontaneous or induced, type and site of rupture, maternal and perinatal outcome, management and complications associated with it were retrieved and was analyzed using SPSS version 16.0

Results: Among 29 uterine rupture cases, majority of cases occurred in 25-29 years (48.3\%), paral (79.3\%) and unbooked cases (72.4\%). Most of them occurred in previous scar 23(79.3\%); rupture was complete in 13 and incomplete in 10 cases. Six $(20.6 \%)$ were unscarred uterine rupture. Rupture repair was done in $24(82.7 \%)$ and peripartum hysterectomy (subtotal hysterectomy) in $5(17.2 \%)$ cases. The most common complications were postpartun hemorrhage (55.2\%), hospital stay $>7$ days (55.2\%), blood transfusion (48.3\%) and ICU admission (41.3\%). There was no maternal mortality. Perinatal death was $15(51.7 \%)-13$ stillbirths and 2 neonatal deaths.

Conclusions: Majority of the uterine rupture occurred in previous scar (79.3\%). Most of the cases underwent repair of the uterus ( $82.7 \%)$ and remaining were peripartum hysterectomy $(17.2 \%)$. There was no maternal mortality. However, perinatal mortality occurred in $51.7 \%$.

Keywords: peripartum hysterectomies, previous scar, repair of uterus, uterine rupture.

\section{INTRODUCTION}

Uterine rupture is one of the life threatening obstetric complications with grave sequelae to both mother and the fetus. Incidence of rupture uterus varies from $0.3 / 1000$ to $7 / 1000$ deliveries in India accounting for $5-10 \%$ of all maternal deaths. ${ }^{1}$ The incidence in developed and developing countries varies from 1 in 250 to 1 in 5000 deliveries depending upon standard of obstetric care and the population dealt with. Maternal mortality as a consequence of uterine rupture occurs at a rate of $0-1 \%$ in developed and $5-10 \%$ in developing countries. ${ }^{2}$

Uterine rupture is classified as either complete or incomplete. In complete uterine rupture, all the layers of the uterine wall are separated with or without expulsion of the fetus or placenta. In incomplete uterine rupture, there is separation of the uterine muscle, but the visceral peritoneum is intact. ${ }^{3}$

\section{CORRESPONDENCE}

Dr Beemba Shakya

Paropakar Maternity and Women's Hospital, Thapathali, Kathmandu

Email: bshakya02@gmail.com

Phone No.: 9840185953
In a WHO systematic review of maternal mortality and morbidity, the prevalence of uterine rupture in previous cesarean section was found to be $1 \%{ }^{2}$ Most common causes of uterine rupture include previous scar giving way. Other causes like obstructed labour, injudicious use of oxytocics, previous myomectomy scar, uterine anomaly, direct trauma to uterus and rarely concealed abruption can also cause uterine rupture. Maternal outcome mainly depends on the integrity of previous scar, cause and site of rupture, interval between rupture and surgery, prompt referral and early detection and management. High perinatal mortality of $80-95 \%$ is seen in these cases. ${ }^{4}$

The purpose of this study is to analyze patients' characteristics with uterine rupture in pregnancy.

\section{METHODS}

This was a cross-sectional retrospective study performed at Paropakar Maternity and Women's 
Hospital (PMWH),Thapathali, Kathmandu. Ethical approval was taken from the hospital IRC. The medical records of uterine rupture in pregnancy were reviewed from April 14, 2017 to April 13, 2019. The charts were collected from medical record section. Data pertaining patient characteristics, age, parity, mode of previous deliveries, onset of labour spontaneous or induced, type and site of rupture, maternal and perinatal outcome, management and complications associated with it were retrieved and was analyzed using SPSS version 16.0.

\section{RESULTS}

A total of 29 cases of uterine rupture in pregnancy were recorded in two years. During this period, total number of deliveries was 39607 including 11269 Cesarean Sections. The rate of cesarean section in this hospital during the study period was $28.4 \%$. The incidence of uterine rupture was $0.07 \%$. Majority of ruptures were in age group of 25-29 years, multipara and scarred uterus [Table-1].

Table-1: Characteristics of patients $(n=29)$

\begin{tabular}{|l|l|}
\hline Characteristics & N (\%) \\
\hline Age (years) & $1(3.4)$ \\
\hline $15-19$ & $7(24.1)$ \\
\hline $20-24$ & $14(48.3)$ \\
\hline $25-29$ & $4(13.8)$ \\
\hline $30-34$ & $3(10.3)$ \\
\hline $35-39$ & \\
\hline Parity & $1(3.4)$ \\
\hline P0 & $23(79.3)$ \\
\hline P1 & $4(13.8)$ \\
\hline P2 & $1(3.4)$ \\
\hline P3 & \\
\hline Booking status & $8(27.6)$ \\
\hline Booked & $21(72.4)$ \\
\hline Unbooked & \\
\hline Status of uterus & $23(79.3)$ \\
\hline Previous scarred uterus & $6(20.6 \%)$ \\
\hline Previous unscarred uterus & \\
\hline
\end{tabular}

Regarding unscarred uterine rupture, four cases presented to emergency department, each presented with fetal distress, vaginal bleeding, hanging breech and septic shock. Of the remaining, one was induced with Misoprostol and another had precipitate labour.

Besides six unscarred uterine rupture 23 had past Cesarean Section. Among previous scarred uterus, previous one lower segment cesarean section (LSCS) were 20 cases and previous two LSCS were 3 cases; and 13 had complete rupture and 10 with incomplete rupture.
Repair of rupture was done in $24(82.7 \%)$ and peripartum hysterectomy (subtotal hysterectomy) in $5(17.2 \%)$ cases. Among twenty four cases of uterine repair five underwent bilateral tubal ligation as well.

Common complications were postpartum hemorrhage $(\mathrm{PPH})$, prolonged hospital stay, blood transfusion and ICU admission [Table-2].

Table-2: Complications

\begin{tabular}{l|l}
\hline Complications & $\mathbf{n}(\%)$ \\
\hline Postpartum hemorrhage (PPH) & $16(55.2)$ \\
\hline Hospital stay $>7$ days & $16(55.2)$ \\
\hline Blood transfusion & $14(48.3)$ \\
\hline ICU admission & $12(41.3)$ \\
\hline Peripartum hysterectomy & $5(17.2)$ \\
\hline Bladder injury & $2(6.9)$ \\
\hline Septicemia & $1(3.4)$ \\
\hline
\end{tabular}

There was no maternal mortality. Perinatal mortality was $15(51.7 \%) ; 13$ were stillbirth and 2 neonatal deaths (NND) both weighing 1100 grams.

\section{DISCUSSION}

The incidence of uterine rupture in this study was $0.07 \%$ which was similar to a study by Sinha et al. ${ }^{5}$ $(0.06 \%)$.

Majority of the cases were in the age group of 20 29 years $(72.4 \%)$ which was similar to the study by Sahu et al. ${ }^{1}$ (73.1\%). Most of them were parity one $(79.3 \%)$ which was in contrary to other studies done by Pritam et al. ${ }^{6}$ and Beck et al. ${ }^{7}$ where rupture was seen in multiparity. This could be because this study had more of previous scar ruptures.

In this study, 21 (72.4\%) were unbooked cases which was comparable with Kalewad et al. ${ }^{3}$ and Pritam et al. ${ }^{6}$ which showed $65.3 \%$ and and $77.1 \%$ respectively.

Rupture of previous cesarean scar was the most common cause of uterine rupture (79.2\%) which was similar $(80 \%)$ to the study conducted by Sunanda et al. $^{8}$ Various other studies ${ }^{1,3,6}$ also revealed the scar rupture as the most common cause revealing 50.6\%, $66 \%$ and $48.5 \%$ respectively. In this study, among the previous cesarean scar, 13/23 were complete rupture and 10/23 were incomplete rupture. Ahmed et al. ${ }^{9}$ observed 76 complete rupture and 10 incomplete ruptures and $\mathrm{Admassu}{ }^{10}$ observed 62 complete rupture and 8 incomplete ruptures depicting more of complete ruptures in these studies.

Regarding unscarred uterine rupture in this study, 
most of them were spontaneous ruptures and reached the hospital late, another was malpresentation with fetal congenital anomaly (hydrocephalus) presented with hanging breech and the next was induced with misoprostol. Spontaneous rupture and late arrival at hospital was also seen in the study by Beck et al. ${ }^{7}$ Spontaneous rupture was also the commonest type observed in Naik et $\mathrm{al}^{11}$, Amanael et $\mathrm{al}^{12}$ and Khan et $\mathrm{a}^{13}$ studies. Obstructed labour, malpresentation and mutiparity were the leading causes of uterine rupture in studies conducted by Diab ${ }^{14}$ and Ezechi et al. ${ }^{15}$

In this study, most of the cases of uterine rupture underwent repair $24(82.7 \%)$ and peripartum hysterectomy (subtotal hysterectomy) in 5(17.2\%) cases. This is comparable to various other studies by Kalewad et $\mathrm{al}^{3}(66.6 \% / 21 \%)$, Pritam et $\mathrm{al}^{6}$ $(54.2 \% / 20 \%)$, Sunanda et $\mathrm{al}^{8}(75 \% / 25 \%)$, and Sahu et $\mathrm{al}^{16}$ (53.83\% repair), where repair was the commonest than the peripartum hysterectomy. However, Beck et $\mathrm{al}^{7}$ study had more of peripartum hysterectomy $(53.5 \%)$ than the uterine repair $(15 \%)$.

In this study, peripartum hysterectomy $(17.2 \%)$ was lower than Pritam et $\mathrm{al}^{6}$ study and slightly lower than Sunanda et $\mathrm{al}^{8}$ accounting for $45.7 \%$ and $25 \%$ respectively, as majority of the rupture occurred in previous cesarean section and most of them were reparable. In this study, bladder injury was $6.9 \%$ which was similar to study by Beck et $\mathrm{al}^{7}(6.2 \%)$, however, higher incidence was seen in Pritam et al6.,
Sunanda et $\mathrm{al}^{8}$ and Rizwan et $\mathrm{al}^{17}$ revealing $14.2 \%$, $30 \%$ and $21.1 \%$ respectively. Other complications like PPH (55.2\%), blood transfusion $(48.3 \%)$ and ICU admission (41.3\%) were seen which were higher than in Kalewad et al ${ }^{3}$ study depicting $5.8 \%, 14.5 \%$ and $5.8 \%$ respectively as in this study, most of the cases were unbooked and arrived late in the hospital. Hospital stay of $>7$ days was $55.2 \%$ in this study because of prolonged use of catheterization, wound infection and development of post partum gestational hypertension. This finding was slightly higher than in Sunanda et $\mathrm{al}^{8}$ study (45\%).

Fortunately, there was no maternal mortality during the study period. However, different studies $^{6-8,16}$ depicted $11.4 \%, 3.75 \%, 10 \%$ and $3.8 \%$ respectively. Perinatal mortality in this study was $51.7 \%$ as most of the cases were IUFD. In a study by Sunanda et al, ${ }^{8}$ it was $35 \%$ while much higher perinatal mortality was seen in other studies ${ }^{6,7,16}$ revealing $85.7 \%, 97.5 \%$ and $100 \%$ respectively.

\section{CONCLUSIONS}

Majority of the uterine rupture occurred in previous scar $(79.3 \%)$. Most of the cases underwent repair of the uterus $(82.7 \%)$ and remaining were peripartum hysterectomy $(17.2 \%)$. There was no maternal mortality. However, perinatal mortality occurred in $51.7 \%$.

Conflict of interest: None

\section{REFERENCES}

1. Sahu LA. A 10 year analysis of uterine rupture at a teaching institution. J Obstet Gynecol India. 2006;5(6):502-6.

2. Justus Hofmeyr G, Say L. Systematic review: WHO systematic review of maternal mortality and morbidity: the prevalence of uterine rupture. BJOG: Int J Obstet Gynecol 2005; 112:1221-8.

3. Kalewad PS, Bava A, Nandanwar YS. Pregnancy outcome in cases of rupture uterus: a clinical study. Int J Reprod Contracept Obstet Gynecol. 2016;5(9):3098-102

4. Mahbuba, Alam IP. Uterine rupture: Experience of 30 case at Faridpur Medical College Hospital. Faridpur Med Coll J. 2012;7(2):79-81

5. Sinha M, Gupta R, Gupta P, Rani R, Kaur R, Singh R. A seven year review at a tertiary care hospital in New Delhi, India Indian J Community Med. 2016;41(1):45-9

6. Pritam A, Singh P, Kumar S. Study of prevalence and outcome of rupture uterus in a tertiary care centre of Muzaffarpur, Bihar A three year retrospective study. JMSCR. 2019;7(2):634-39.

7. Beck R, Minz DS, Tirkey S, Kumar A, Sen S. Study the cases of rupture uterus in a tertiary care teaching hospital, Jharkhand, India and its maternal and perinatal outcome. Int $J$ Reprod Contracept Obstet Gynecol. 2018;7(3):938-46.

8. Sunanda N, Ranganth P. A two year analysis of uterine rupture in pregnancy. Int $\mathrm{J}$ Reprod Contracept Obstet Gynecol 2016;5(11):3983-6.
9. Ahmed SM, Daffalla SE. Incidence of uterine rupture in teaching hospital, Sudan. Saudi Med J. 2001;22:757-61.

10. Admassu A, Analysis of ruptured uterus in Debre Markos Hospital, Ethiopia. East Afri Med J. 2004;81(1):52-5.

11. Naik B, Gohil JT, Pagi SL. Rupture uterus: A 12 year review J Obstet Gynecol India. 1996;46(3):334-40

12. Amanael G, Mengiste MM. Ruptured uterus - Eight year retrospective analysis of causes and management outcome in Adigrat Hospital, Tigray region, Ethiopia. J Health Dev $2002 ; 16: 241-5$.

13. Khan S, Parveen Z, Begum S, Alam I. Uterine rupture: a review of 34 cases at Ayub Teaching Hospital Abbottabad. JAMC. 2003;15(4):50-2

14. Diab AE. Uterine rupture in Yemen. Saudi Med J 2005;26(2):264-9.

15. Ezechi OC, Mabayoje P, Obsiesie LO. Rupture uterus in South Western Nigeria: a reappraisal. Singapore Med J. 2004;45:113-6.

16. Sahu M, Natasha HK, Mandpe P. Case analysis of complete uterine rupture in a tertiary health care center. Int J Reprod Contracept Obstet Gynecol. 2016;5(12):4401-4.

17. Rizwan N, Abbasi RM, Uddin SF. Uterine rupture, frequency of cases and fetomaternal outcome. J Pak Med Assoc 2011;61(4):322 